Research Article

\title{
Expression of La Ribonucleoprotein Domain Family Member 4B (LARP4B) in Liver Cancer and Their Clinical and Prognostic Significance
}

\author{
Yanqing Li $\mathbb{D}^{1},{ }^{1}$ Yan Jiao $\mathbb{D}^{\circ},{ }^{2}$ Yang Li $\mathbb{D}^{1},{ }^{1}$ and Yanan Liu $\mathbb{D}^{1}$ \\ ${ }^{1}$ Department of Pathophysiology, College of Basic Medical Sciences, Jilin University, Changchun, Jilin 130021, China \\ ${ }^{2}$ Department of Hepatobiliary and Pancreatic Surgery, The First Hospital of Jilin University, Changchun, Jilin 130021, China \\ Correspondence should be addressed to Yang Li; ygli136@163.com and Yanan Liu; ynliu@jlu.edu.cn
}

Received 25 April 2019; Accepted 17 September 2019; Published 22 October 2019

Academic Editor: Paola Gazzaniga

Copyright (c) 2019 Yanqing Li et al. This is an open access article distributed under the Creative Commons Attribution License, which permits unrestricted use, distribution, and reproduction in any medium, provided the original work is properly cited.

\begin{abstract}
Background and Objective. Liver cancer is a common malignant tumor with few poor diagnostic and prognostic markers, which greatly shortens the potential life span of patients. The RNA-binding protein la ribonucleoprotein 4B (LARP4B) has a la motif (lam) that is important in the process of cancer. We aimed to explore the role of LARP4B in the diagnosis and prognosis of liver cancer. Methods. The Cancer Genome Atlas (TCGA) database was searched to detect LARP4B gene expression in liver cancer. The clinical relevance and diagnostic ability of LARP4B were evaluated by a chi-squared test and a receiver operating characteristic (ROC) curve, respectively. Survival and risk factors of patients with liver cancer were assessed by survival analysis and univariate/multivariate Cox regression model. Additionally, we carried out gene set enrichment analysis (GSEA) to identify LARP4B-related signaling pathways in liver cancer. Results. LARP4B mRNA was highly expressed in liver cancer tissues and was correlated with survival status. The chi-squared test showed that LARP4B had clinical relevance, while ROC curves showed that LARP4B had good diagnostic ability. Survival analysis showed that liver cancer patients with high LARP4B expression had shorter overall/relapse-free survival. The univariate/multivariate Cox regression model indicated that high LARP4B expression may be an independent risk factor for the prognosis of liver cancer patients. Finally, we found that genes involved in the G2M checkpoint, E2F targets, and mitotic spindle were differentially enriched in the high LARP4B-expression phenotype. Conclusions. LARP4B is a potential independent biomarker for diagnosis and prognosis in liver cancer patients.
\end{abstract}

\section{Introduction}

Liver cancer is one of the most common malignant tumors in the world [1]. It has a high degree of malignancy, strong invasion and metastasis, and poor prognosis and poses a serious threat to health [2]. Although the number of tumor markers used in the diagnosis and prognosis of related cancers has increased, none have the high recognition, sensitivity, and specificity required to evaluate the condition, efficacy, and prognosis of liver cancer $[3,4]$. There is an urgent need to identify biomarkers with diagnostic and prognostic accuracy.

La ribonucleoprotein $4 \mathrm{~B}$ (LARP4B) is a member of the La-related protein (LARP) family [5]. LARP4B protein is an RNA-binding protein containing lanthanum and adjacent RNA recognition motifs (RRMs) [6], which allow it to partic- ipate in posttranscriptional control of RNA and play an important role in translation $[7,8]$. LARP4B is involved in the progression of many cancers [9]. In gliomas, for example, LARP4B inhibits tumor progression [10]. However, its role in liver cancer has not been explored.

To assess the potential clinical role of LARP4B in liver cancer, we probed TCGA database for the mRNA expression of $L A R P 4 B$ in liver cancer patients. Chi-squared testing was used to assess clinical relevance, ROC curves were used to estimate diagnostic capability, and overall/relapse-free survival analyses were conducted to examine the impact of LARP4B on patients with liver cancer. Univariate/multivariate Cox regression models were used to identify risk factors associated with liver cancer. We also carried out GSEA about the LARP4B-related signaling pathways. 
TABle 1: Demographic and clinical characteristics of the TCGALIHC cohort.

\begin{tabular}{|c|c|}
\hline Characteristics & Number of cases (\%) \\
\hline \multicolumn{2}{|l|}{ Age } \\
\hline$<55$ & $117(31.45)$ \\
\hline$\geq 55$ & $255(68.55)$ \\
\hline NA & $1(0)$ \\
\hline \multicolumn{2}{|l|}{ Gender } \\
\hline Female & $121(32.44)$ \\
\hline Male & $252(67.56)$ \\
\hline \multicolumn{2}{|l|}{ Histological type } \\
\hline Fibrolamellar carcinoma & $3(0.8)$ \\
\hline Hepatocellular carcinoma & $363(97.32)$ \\
\hline Hepatocholangiocarcinoma (mixed) & $7(1.88)$ \\
\hline \multicolumn{2}{|l|}{ Histologic grade } \\
\hline NA & $5(1.34)$ \\
\hline G1 & $55(14.75)$ \\
\hline G2 & $178(47.72)$ \\
\hline G3 & $123(32.98)$ \\
\hline G4 & $12(3.22)$ \\
\hline \multicolumn{2}{|l|}{ Stage } \\
\hline NA & $24(6.43)$ \\
\hline I & $172(46.11)$ \\
\hline II & $87(23.32)$ \\
\hline III & $85(22.79)$ \\
\hline IV & $5(1.34)$ \\
\hline \multicolumn{2}{|l|}{ T classification } \\
\hline NA & $2(0.54)$ \\
\hline $\mathrm{T} 1$ & $182(48.79)$ \\
\hline $\mathrm{T} 2$ & $95(25.47)$ \\
\hline T3 & $80(21.45)$ \\
\hline $\mathrm{T} 4$ & $13(3.49)$ \\
\hline TX & $1(0.27)$ \\
\hline \multicolumn{2}{|l|}{$\mathrm{N}$ classification } \\
\hline NA & $1(0.27)$ \\
\hline No & $253(67.83)$ \\
\hline N1 & $4(1.07)$ \\
\hline $\mathrm{NX}$ & $115(30.83)$ \\
\hline \multicolumn{2}{|l|}{ M classification } \\
\hline M0 & $267(71.58)$ \\
\hline M1 & $4(1.07)$ \\
\hline MX & $102(27.35)$ \\
\hline \multicolumn{2}{|l|}{ Radiation therapy } \\
\hline NA & $25(6.7)$ \\
\hline No & 340 (91.15) \\
\hline Yes & $8(2.14)$ \\
\hline \multicolumn{2}{|l|}{ Residual tumor } \\
\hline NA & $7(1.88)$ \\
\hline R0 & $326(87.4)$ \\
\hline $\mathrm{R} 1$ & $17(4.56)$ \\
\hline $\mathrm{R} 2$ & $1(0.27)$ \\
\hline
\end{tabular}

TABle 1: Continued.

\begin{tabular}{lc}
\hline Characteristics & Number of cases (\%) \\
\hline RX & $22(5.9)$ \\
Vital status & \\
Deceased & $130(34.85)$ \\
Living & $243(65.15)$ \\
Sample type & \\
Primary tumor & $371(99.46)$ \\
Recurrent tumor & $2(0.54)$ \\
LARP4B & \\
High & $253(67.83)$ \\
Low & $120(32.17)$ \\
\hline
\end{tabular}

Abbreviation: NA: not available.

\section{Materials and Methods}

2.1. Data Source. We obtained currently available clinical and RNA sequence data about normal and liver cancer tissues from TCGA (https://cancergenome.nih.gov/). No ethical permission was required because all of the data used in this paper were made available for research.

2.2. Data Mining and Statistical Analyses. We used the R software environment (version 3.6.1) for data mining [11]. Boxplots of clinical features were drawn with the ggplot2 package [12]. The ROC curve was drawn by pROC [13], which is based on a series of different binary classifications (demarcation value or determination threshold), plotting the true positive rate (sensitivity) as the ordinate and the false positive rate (1-specificity) as the abscissa. Among them, the area under the ROC curve (AUC) is used to measure the diagnostic performance. The chi-squared test was used to identify possible clinical correlations between clinical features and $L A R P 4 B$ expression. We also used survival packages to plot survival curves, and a logarithmic rank test to check survival bias [14]. Univariate and multivariate Cox models were used to distinguish risk factors associated with liver cancer [15].

2.3. GSEA. GSEA is used to classify gene probes based on related biological pathways published in authoritative journals and coexpression data obtained from experiments. To determine correlation, a series of operations are carried out to determine whether the probes can reveal a distribution pattern of genes related to the phenotype of interest [16]. In this research, we used the gene set of "h.all.v6.2.symbols.gmt" from the Molecular Signatures Database to perform GSEA in GSEA 3.0 software. Through the analysis of 1,000 permutations, we obtained the standardized enrichment fraction and calculated a normalized enrichment score.

\section{Results}

3.1. Data Overview. The LARP4B expression level and clinical features of the TCGA liver cancer cohort include gender, age, 


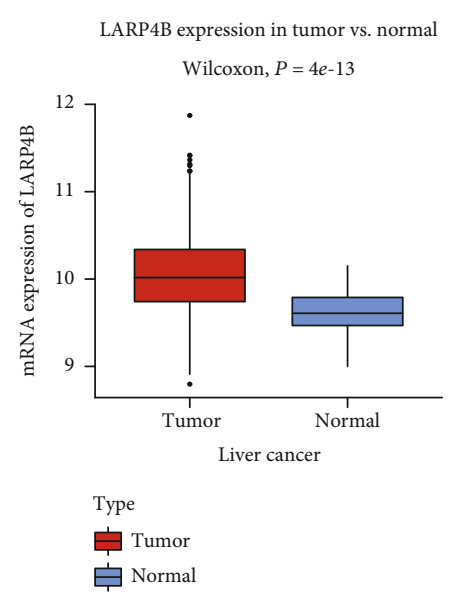

(a)

LARP4B expression grouped by gender

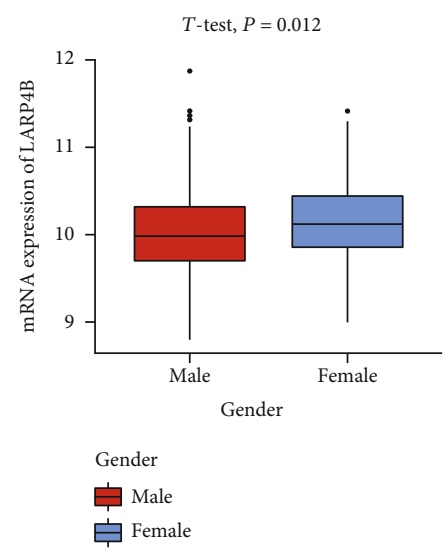

(d)

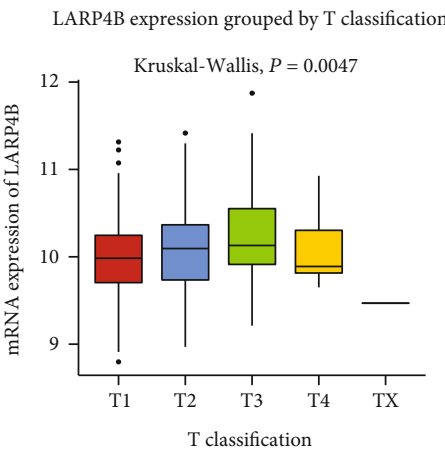

Type

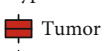

官 Normal

(g)
LARP4B expression grouped by vital status

Wilcoxon, $P=0.03$

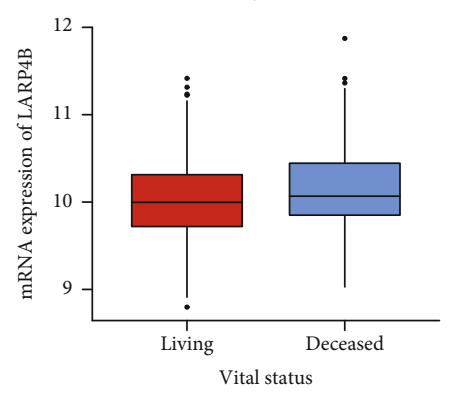

Vital_status

它 Living

追Deceased

(b)

LARP4B expression grouped by histologic grade

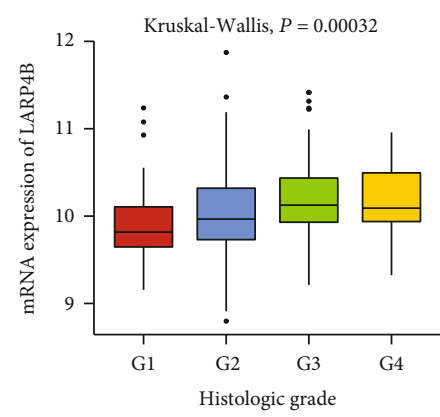

Histologic_grade

官G1 自 F3 $^{\text {G }}$

(e)

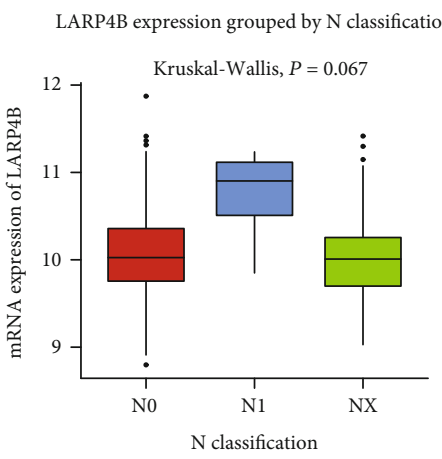

$\mathrm{N}$ classification

N0

官 1

它 $N x$

(h)
LARP4B expression grouped by age

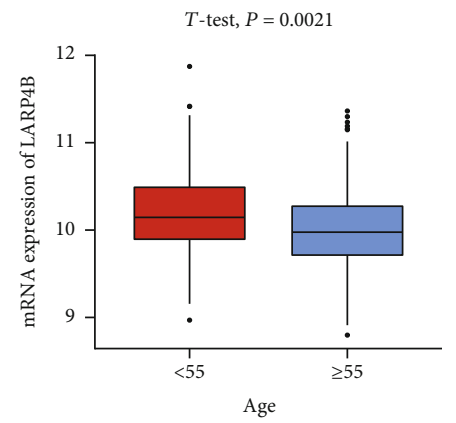

Age

$$
\begin{aligned}
& \text { 崖 }>55 \\
& \text { <5 }
\end{aligned}
$$

(c)

LARP4B expression grouped by histological type

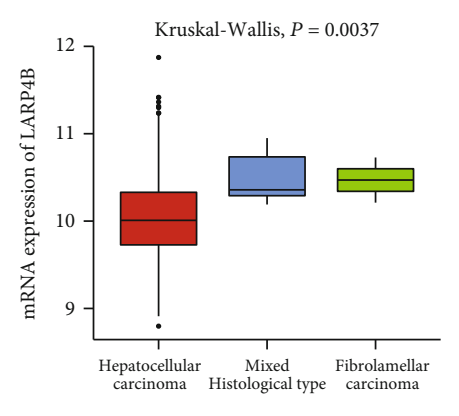

Histological_type

自 Hepatocellular carcinoma

官 Hepatocholangiocarcinoma (mixed)

官 Fibrolamellar carcinoma

(f)

LARP4B expression grouped by $M$ classification Kruskal-Wallis, $P=0.21$

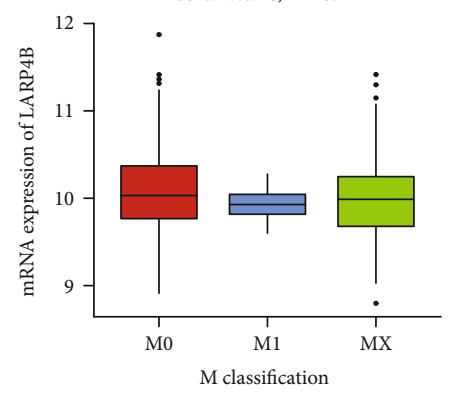

M_classification

$\biguplus \mathrm{M} 0$

M1

$\mathrm{FX}_{\mathrm{M}}$

FIgure 1: Continued. 


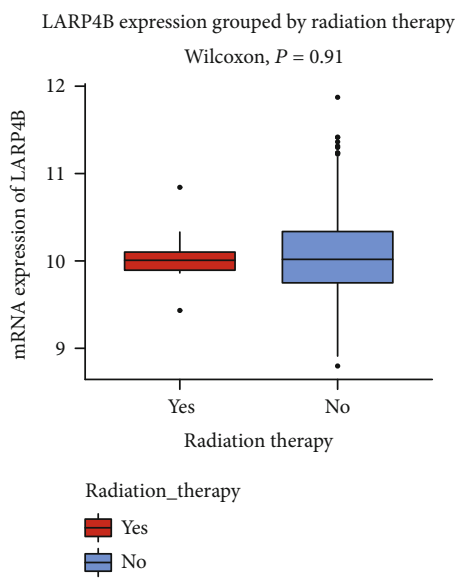

(j)

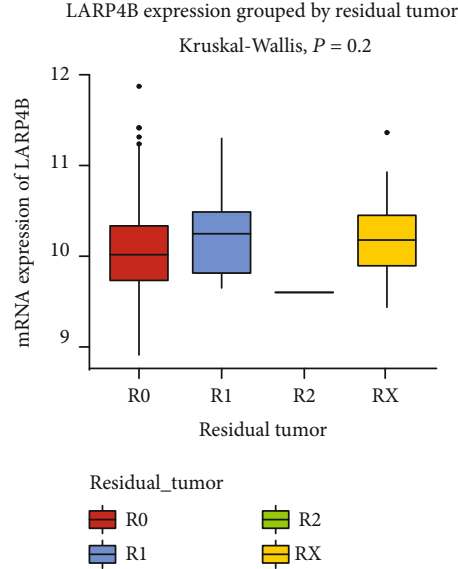

(k)

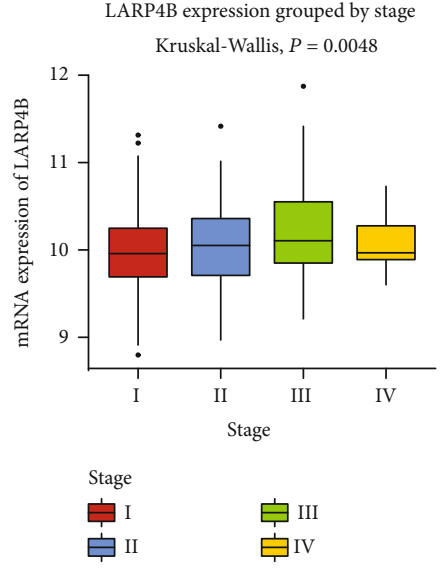

(1)

Figure 1: Boxplots showing $L A R P 4 B$ expression according to clinical stage and tissue type.

histologic type and grade, sample type, T/N/M classification, radiation therapy, residual tumor, vital status, stage, and relapse (Table 1).

3.2. LARP4B Expression in Normal and Liver Cancer Tissues. Boxplots showed higher LARP $4 B$ mRNA expression in liver cancer tissues compared with normal liver tissues $(P=4 e-13$; Figure 1). Furthermore, there were significant differences in $L A R P 4 B$ expression with regard to vital status $(P=0.03)$, stage $(P=0.0046)$, gender $(P=0.012)$, age $(P=$ $0.0021)$, histologic grade $(P=0.00032)$, type $(P=0.0037)$, and $\mathrm{T}$ classification $(P=0.047)$.

3.3. Diagnostic Capability of LARP4B in Liver Cancer. ROC curves revealed that AUC was 0.816 , indicating that $L A R P 4 B$ might have considerable diagnostic ability (Figure 2(a)). This result was confirmed in subsequent subgroup analysis of the different stages (AUC: $0.784,0.795,0.884$, and 0.872 for stage I, stage II, stage III, and stage IV, respectively; Figures 2(b)-2(e)).

3.4. High LARP4B Expression Was Relevant to Clinical Features of Liver Cancer. As shown in Table 2, the expression of $L A R P 4 B$ was clearly related to age $(P=0.0274)$, gender $(P=0.0256)$, vital status $(P=0.0301)$, and histologic grade $(P=0.0003)$ of liver cancer patients.

3.5. Increased LARP4B Expression Was Related to Poor Overall Survival in Liver Cancer. As shown in Figure 3, the high expression of $L A R P 4 B$ in patients was correlated with poor overall survival $(P=0.0095)$. Subgroup analysis showed that $L A R P 4 B$ expression had significant prognostic value in liver cancer patients who were older $(P=0.0049)$, T3 $(P=0.012)$, G1/G2 $(P=0.016)$, male $(P=0.01)$, and R0 $(P=0.013)$.

A univariate Cox model revealed that residual tumor, stage, $\mathrm{T}$ classification, and $L A R P 4 B$ expression represented potential survival-related variables. A multivariate Cox model suggested that a high $L A R P 4 B$ expression was a potential independent risk factor for patient's overall survival with liver cancer (95\% confidence interval (CI) 1.1-2.46, $P=0.016$, hazard ratio $(\mathrm{HR})=1.64$; Table 3 ).

3.6. Increased LARP4B Expression Was Related to Poor Relapse-Free Survival in Liver Cancer. As shown in Figure 4, there was a high expression of $L A R P 4 B$ in patients with relapse-free survival $(P=0.044)$. Subgroup analysis showed that $L A R P 4 B$ expression had a prognostic value in liver cancer patients who were T4 $(P=0.049)$, male $(P=0.014)$, stage III/IV $(P=0.037)$, G1/G2 $(P=0.022)$, and older $(P=0.024)$.

A univariate Cox model showed that residual tumor, stage, $\mathrm{T}$ classification, and $L A R P 4 B$ expression represented potential relapse-free survival-related variables. A multivariate Cox model suggested that a high $L A R P 4 B$ expression was a potential independent risk factor for relapse-free survival in liver cancer patients (95\% CI $1-2.13, P=0.048, \mathrm{HR}=1.46$; Table 4).

3.7. LARP4B-Related Signaling Pathway. To identify the activated signal pathways in liver cancer, GSEA was conducted between the low $L A R P 4 B$ expression and high $L A R P 4 B$ expression datasets. GSEA revealed significant differences in the enrichment of the MSigDB Collection (h.all.v6.2.symbols.gmt; NOM $P$ value $<0.05$, FDR $<0.25$; Table 5). Genes related to E2F, G2M, and the mitotic spindle (Figure 5; Table 5) were enriched in the high LARP4B expression phenotype, which may represent an intrinsic mechanism of poor prognosis.

\section{Discussion}

Viral infection, diet, environmental problems, and other factors have contributed to the high mortality rate of liver cancer worldwide [17]. Continuous advances in surgical technology, chemotherapeutic drugs, and molecular biology have furthered our understanding of cancer biology, and there has been great progress in the treatment of liver cancer in recent years. In this study, we have applied our extensive 


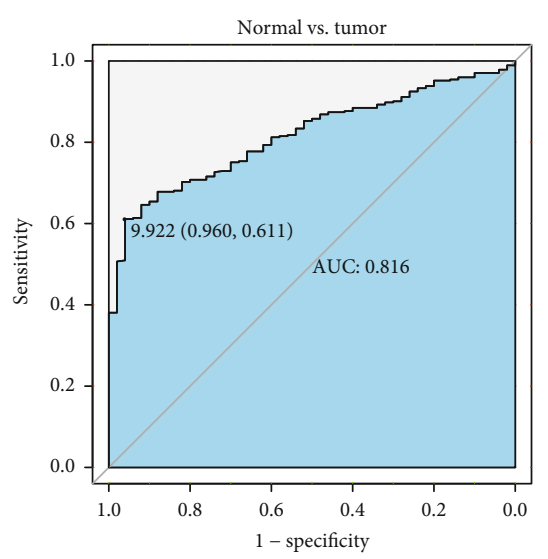

(a)

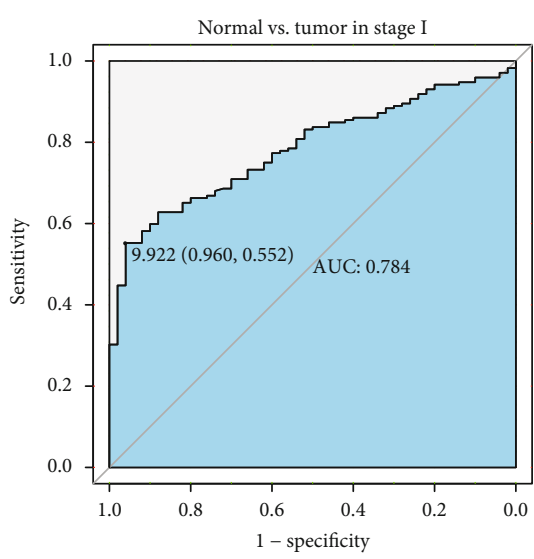

(b)

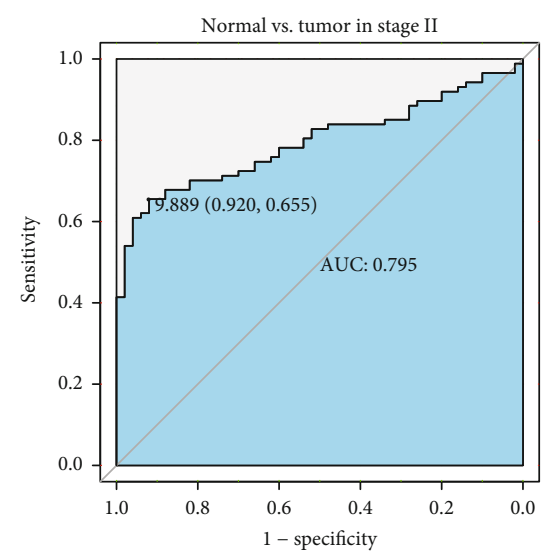

(c)

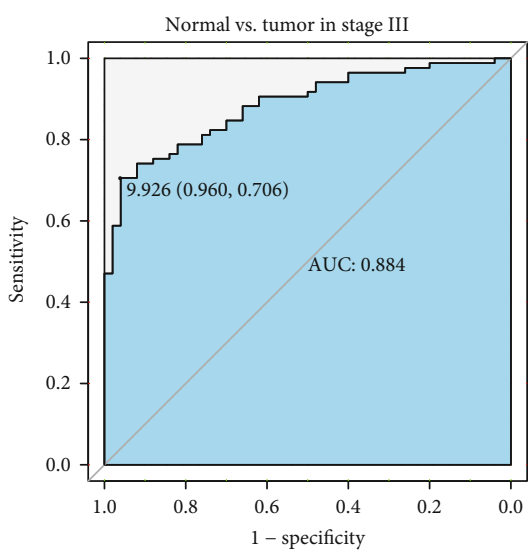

(d)

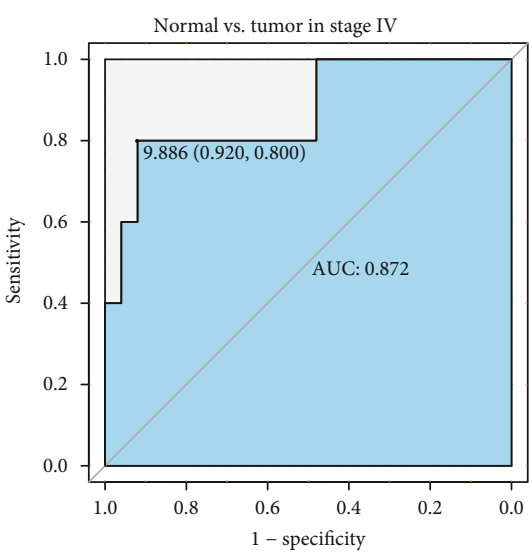

(e)

Figure 2: ROC curves of LARP4B expression in the TCGA-LIHC cohort. Normal liver vs. liver tumor samples (a). Normal liver vs. stage I (b), stage II (c), stage III (d), and stage IV (e) liver tumor samples. AUC: area under the curve; LIHC: liver hepatocellular carcinoma; ROC: receiver operating characteristic curve.

experience in the exploration of novel biomarkers [18-23] to identify a biomarker, LARP4B, for the diagnosis and prognosis of patients with liver cancer.

The involvement of LARP4B has been documented in many cancer processes, including medulloblastoma [24], malignant peripheral nerve sheath tumors [25], colorectal cancer [26], pancreatic cancer [27], and glioma [10]. In contrast to our results, Koso et al. [10] found low expression of LARP4B in gliomas, which suggests that LARP4B may play different roles in different cancers. In addition, the boxplots showed that $L A R P 4 B$ expression was statistically significantly associated with vital status, age, gender, histologic grade and type, stage, and T classification. Therefore, it is necessary to further explore the role of LARP4B in liver cancer.

Low LARP4B expression was closely related to poor prognosis in glioma cancer patients in the study by Koso et al. [10]. No such relationship between LARP4B and prognosis has been found in liver cancer. In this study, we found that overexpressed $L A R P 4 B$ was associated with a poor prognosis in liver cancer patients, which may be attributable to the different functions of LARP4B in differ- ent tissues. LARP4B overexpression also led to shorter overall/relapse-free survival. Subgroup analysis of overall survival showed especially poor prognoses in patients who were male, T3, G1/G2, older, and R0, while relapsefree survival was correlated with patients who were male, T4, G1/G2, older, and stage III/IV. This distinction could be applied to the precise, individualized treatment of liver cancer patients. Calculation of AUC from the ROC curves showed the validity of clinical diagnostic testing of LARP4B. Our results suggest that LARP4B has strong potential as a marker in the clinical detection of liver cancer patients.

The progression of cancer requires a complete cell cycle [28]. Genes related to E2F, G2M, and the mitotic spindle are important signaling pathways in the cell cycle [29-31]. Interestingly, we found that E2F, G2M, and mitotic spindle signaling pathways were all involved in the progression of liver cancer. LARP4B is a posttranscriptional regulator and may regulate the roles of downstream genes through these three sets of target molecules. In addition, Zhang et al. [32] found that LARP4B may regulate the cell cycle of leukemia stem cells by inhibiting the expression of cell cycle inhibitors p16, P19, and p21 and myeloid-specific transcription 
TABLE 2: Correlation between the expression of LARP4B and the clinic pathologic characteristics in liver cancer.

\begin{tabular}{|c|c|c|c|c|c|c|c|c|}
\hline \multirow{2}{*}{ Clinical characteristics } & \multirow{2}{*}{ Variable } & \multirow{2}{*}{ No. of patients } & \multicolumn{4}{|c|}{ LARP4B expression } & \multirow{2}{*}{$X^{2}$} & \multirow{2}{*}{$P$} \\
\hline & & & High & $\%$ & Low & $\%$ & & \\
\hline \multirow{2}{*}{ Age } & $<55$ & 117 & 89 & 35.32 & 28 & 23.33 & 4.8736 & 0.0273 \\
\hline & $\geq 55$ & 255 & 163 & 64.68 & 92 & 76.67 & & \\
\hline \multirow{2}{*}{ Gender } & Female & 121 & 92 & 36.36 & 29 & 24.17 & 4.9824 & 0.0256 \\
\hline & Male & 252 & 161 & 63.64 & 91 & 75.83 & & \\
\hline \multirow{3}{*}{ Histological type } & Fibrolamellar carcinoma & 3 & 3 & 1.19 & 0 & 0 & 4.8737 & 0.0874 \\
\hline & Hepatocellular carcinoma & 363 & 243 & 96.05 & 120 & 100 & & \\
\hline & Hepatocholangiocarcinoma (mixed) & 7 & 7 & 2.77 & 0 & 0 & & \\
\hline \multirow{4}{*}{ Histologic grade } & G1 & 55 & 27 & 10.8 & 28 & 23.73 & 18.9592 & 0.0003 \\
\hline & G2 & 178 & 115 & 46 & 63 & 53.39 & & \\
\hline & G3 & 123 & 98 & 39.2 & 25 & 21.19 & & \\
\hline & G4 & 12 & 10 & 4 & 2 & 1.69 & & \\
\hline \multirow{4}{*}{ Stage } & I & 172 & 108 & 45.96 & 64 & 56.14 & 4.4368 & 0.218 \\
\hline & II & 87 & 59 & 25.11 & 28 & 24.56 & & \\
\hline & III & 85 & 64 & 27.23 & 21 & 18.42 & & \\
\hline & IV & 5 & 4 & 1.7 & 1 & 0.88 & & \\
\hline \multirow{5}{*}{ T classification } & $\mathrm{T} 1$ & 182 & 117 & 46.25 & 65 & 55.08 & 6.9572 & 0.1382 \\
\hline & $\mathrm{T} 2$ & 95 & 66 & 26.09 & 29 & 24.58 & & \\
\hline & $\mathrm{T} 3$ & 80 & 62 & 24.51 & 18 & 15.25 & & \\
\hline & $\mathrm{T} 4$ & 13 & 8 & 3.16 & 5 & 4.24 & & \\
\hline & $\mathrm{TX}$ & 1 & 0 & 0 & 1 & 0.85 & & \\
\hline \multirow{3}{*}{$\mathrm{N}$ classification } & No & 253 & 174 & 69.05 & 79 & 65.83 & 2.6345 & 0.2679 \\
\hline & N1 & 4 & 4 & 1.59 & 0 & 0 & & \\
\hline & NX & 115 & 74 & 29.37 & 41 & 34.17 & & \\
\hline \multirow{3}{*}{ M classification } & M0 & 267 & 188 & 74.31 & 79 & 65.83 & 3.2303 & 0.1989 \\
\hline & M1 & 4 & 3 & 1.19 & 1 & 0.83 & & \\
\hline & MX & 102 & 62 & 24.51 & 40 & 33.33 & & \\
\hline \multirow{2}{*}{ Radiation therapy } & No & 340 & 233 & 97.08 & 107 & 99.07 & 0.5773 & 0.4474 \\
\hline & Yes & 8 & 7 & 2.92 & 1 & 0.93 & & \\
\hline \multirow{4}{*}{ Residual tumor } & R0 & 326 & 223 & 88.49 & 103 & 90.35 & 2.9922 & 0.3928 \\
\hline & $\mathrm{R} 1$ & 17 & 12 & 4.76 & 5 & 4.39 & & \\
\hline & $\mathrm{R} 2$ & 1 & 0 & 0 & 1 & 0.88 & & \\
\hline & $\mathrm{RX}$ & 22 & 17 & 6.75 & 5 & 4.39 & & \\
\hline \multirow{2}{*}{ Sample type } & Primary tumor & 371 & 252 & 99.6 & 119 & 99.17 & 0 & 1 \\
\hline & Recurrent tumor & 2 & 1 & 0.4 & 1 & 0.83 & & \\
\hline \multirow{2}{*}{ Vital status } & Deceased & 130 & 98 & 38.74 & 32 & 26.67 & 4.7032 & 0.0301 \\
\hline & Living & 243 & 155 & 61.26 & 88 & 73.33 & & \\
\hline
\end{tabular}

factor CCAAT enhancer binding protein alpha. However, Mattijssen and Maraia [33] found that LARP4B participated in the regulation of TNF-alpha-TTP as its functional activity in MLL-AF9 leukemia stem cells. It is possible that LARP4B participates in the progression of different cancers through multiple signaling pathways.

As far as we know, this is the first study to examine the diagnostic and prognostic values of $L A R P 4 B$ expression in liver cancer. Together with other studies on the functions of LARP4B, we have contributed to a better understanding of the role of LARP $4 B$ and expanded the possibilities for more precise diagnosis and prognosis in cancer. We plan to continue exploring the functions of LARP4B to clarify its underlying mechanism in tumorigenesis at a deeper level.

\section{Conclusion}

In this investigation of LARP4B in the prognosis and diagnosis of liver cancer, we identified high LARP4B expression as a potential independent biomarker for negative prognosis. We 


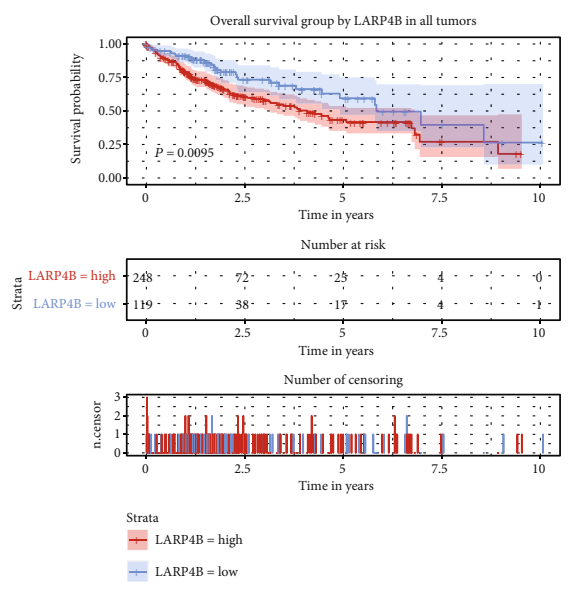

(a)

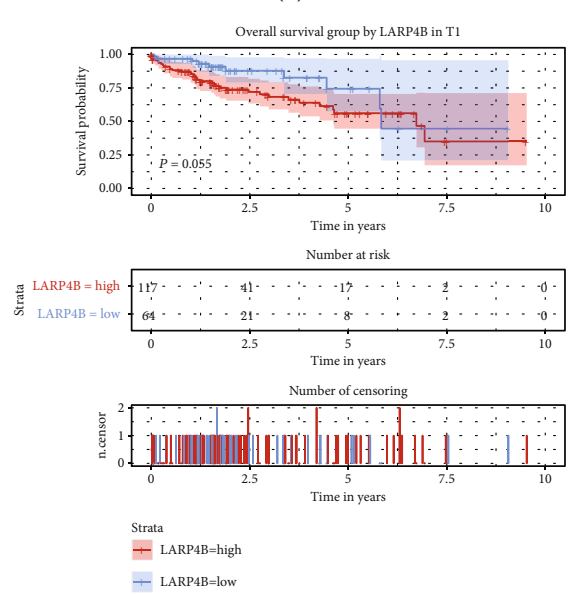

(d)

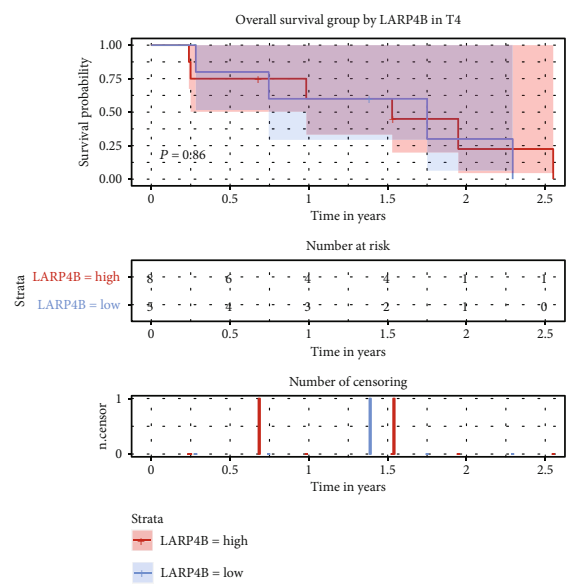

(g)
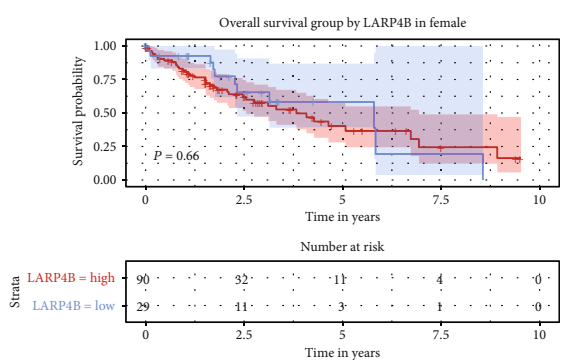

Number of censoring

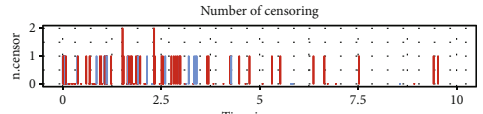

$\begin{aligned} & \text { Strata } \\ & + \text { LARPAB }\end{aligned}=$ high

TARP4B $=$ high
+ LARPAB $=$ low

(b)

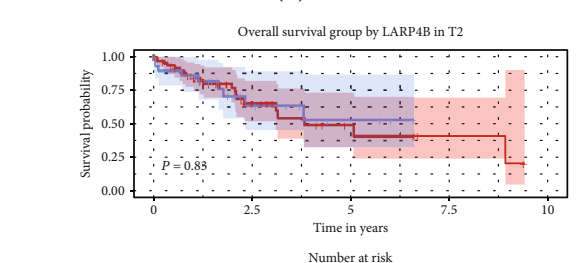

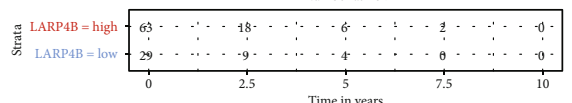

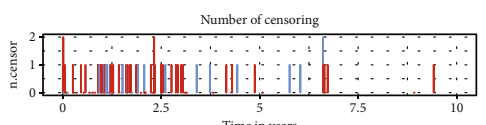

Strata
+ LARP4B $=$ high

- LARP4B = low

(e)

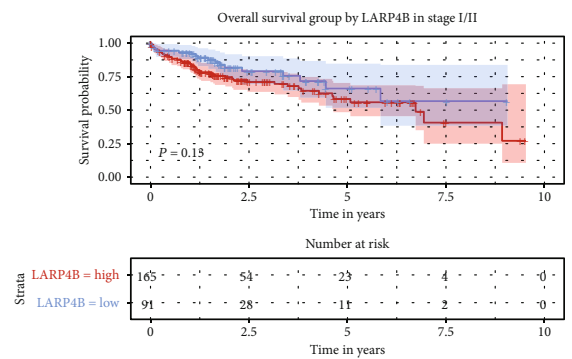

Number of censorin

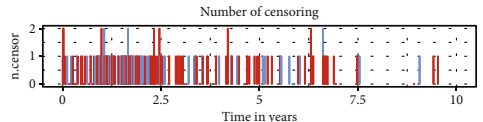

Strat

Strata
+ LARP4B $=$ high

+LARP4B = low

(h)

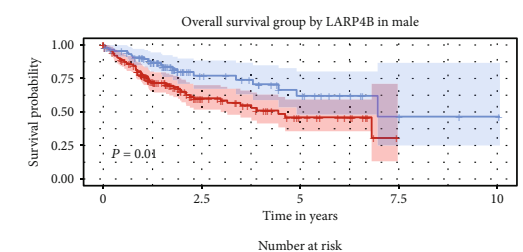

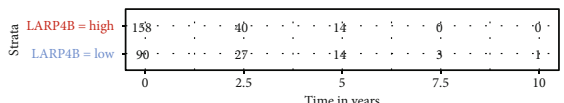

Number of censoring

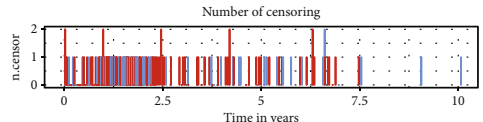

Strata

+ LARP4B = high

- LARP4B $=$ low

(c)

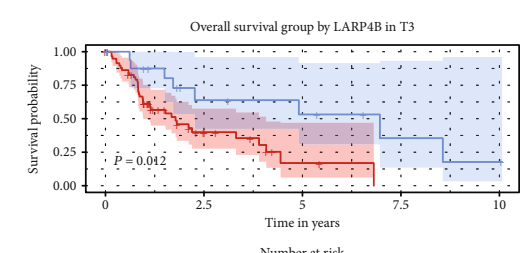

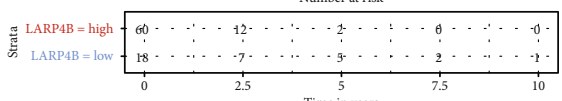

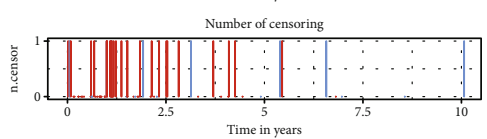

Strata

+ LARP4B = high

- LARP4B $=$ low

(f)
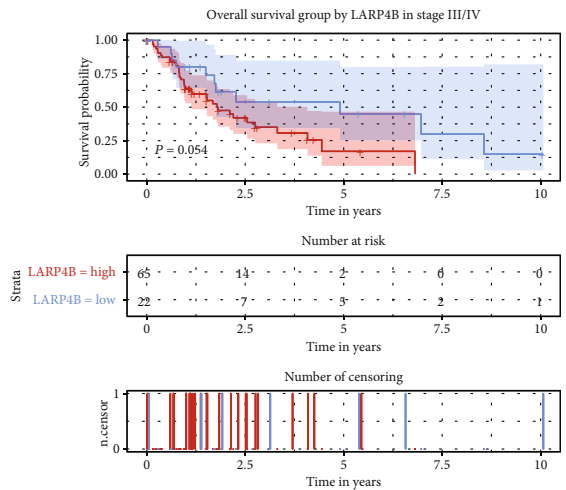

Strata

Strata
- LARP4B

- LARP4B = low

(i)

Figure 3: Continued. 


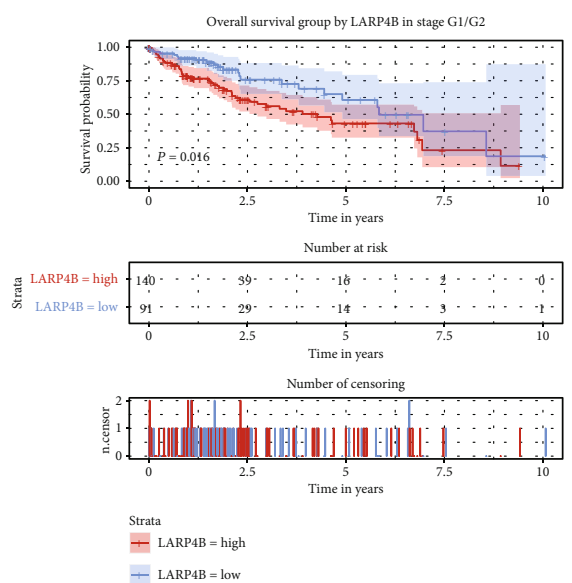

(j)

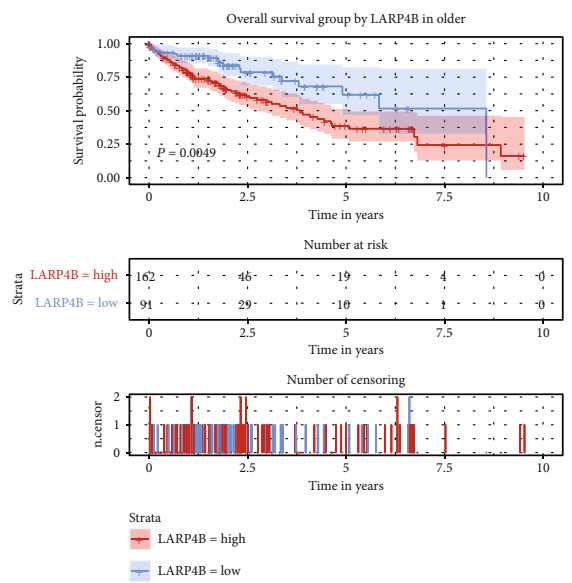

(m)
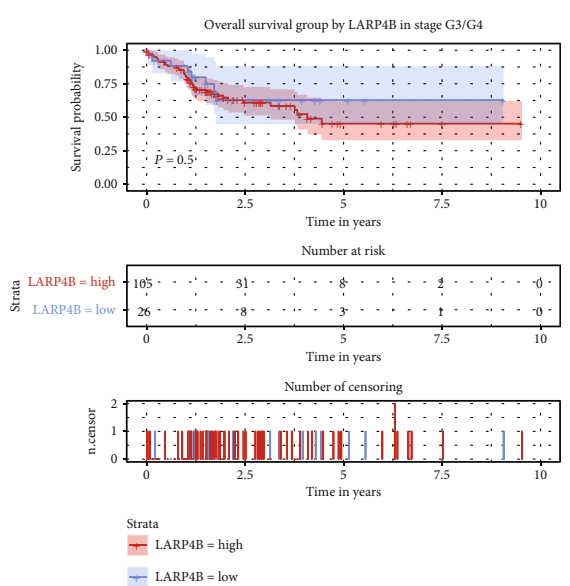

- LARP4B = low

(k)

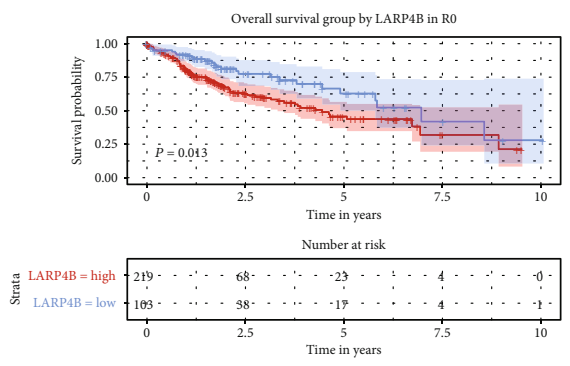

Number of censoring

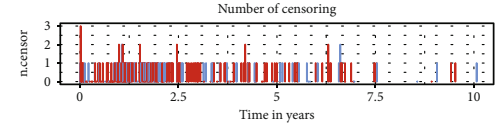

Strata
+ LARP4B $=$ high
$+\quad$ LARP4B $=$ low

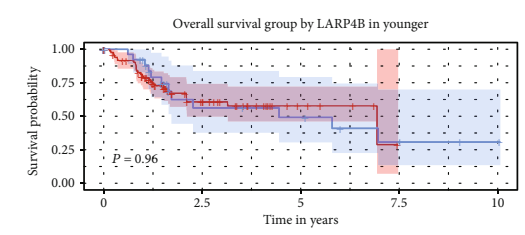

Number at risk

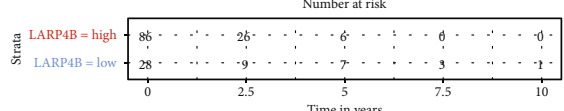

Number of censoring

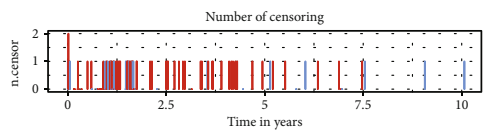

Strata
- LARP $4 \mathrm{~B}=$ high

+ LARP4B $=$ low

(1)

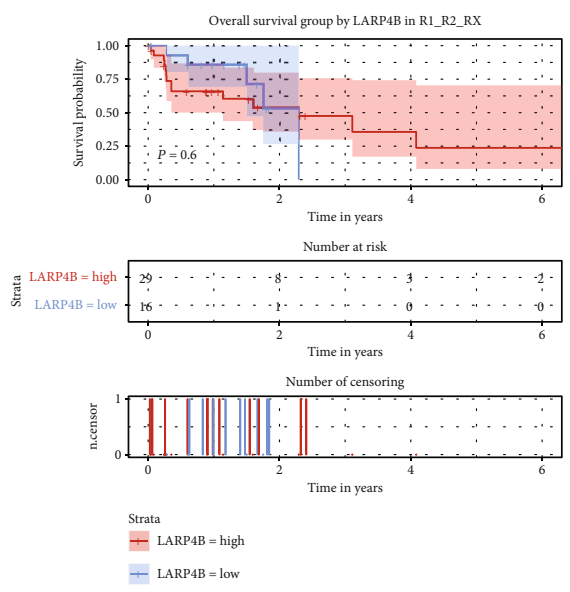

(o)

FIGURE 3: Effect of $L A R P 4 B$ expression on overall survival in subgroups of patients with liver cancer. Kaplan-Meier curves of overall survival analysis (a) and subgroup analysis of gender (female and male) (b, c), T classification (T1/T2/T3/T4) (d-g), clinical stage (I/II and III/IV) $(h, i)$, histologic grade (G1/G2 and G3/G4) (j, k), age (younger and older) (l, m), and lymph node dissection (R0 and R1/R2/RX) (n, o).

TABLE 3: Summary of univariate and multivariate Cox regression analyses of overall survival duration.

\begin{tabular}{|c|c|c|c|c|c|c|}
\hline \multirow{2}{*}{ Parameters } & \multicolumn{3}{|c|}{ Univariate analysis } & \multicolumn{3}{|c|}{ Multivariate analysis } \\
\hline & Hazard ratio & 95\% CI (lower upper) & $P$ value & Hazard ratio & 95\% CI (lower-upper) & $P$ value \\
\hline Age & 1 & $0.69-1.45$ & 0.997 & & & \\
\hline Gender & 0.8 & $0.56-1.14$ & 0.22 & & & \\
\hline Histological type & 0.99 & $0.27-3.66$ & 0.986 & & & \\
\hline Histologic grade & 1.04 & $0.84-1.3$ & 0.698 & & & \\
\hline Stage & 1.38 & $1.15-1.66$ & 0.001 & 0.87 & $0.7-1.08$ & 0.203 \\
\hline $\mathrm{T}$ classification & 1.66 & $1.39-1.99$ & 0 & 1.85 & $1.46-2.34$ & 0 \\
\hline $\mathrm{N}$ classification & 0.73 & $0.51-1.05$ & 0.086 & & & \\
\hline M classification & 0.72 & $0.49-1.04$ & 0.077 & & & \\
\hline Radiation therapy & 0.51 & $0.26-1.03$ & 0.06 & & & \\
\hline Residual tumor & 1.42 & $1.13-1.8$ & 0.003 & 1.39 & $1.08-1.78$ & 0.01 \\
\hline LARP4B & 1.69 & $1.13-2.52$ & 0.01 & 1.64 & $1.1-2.46$ & 0.016 \\
\hline
\end{tabular}




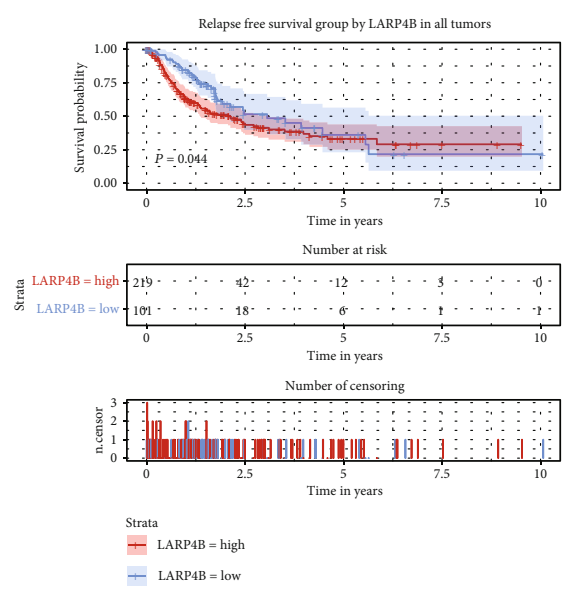

(a)
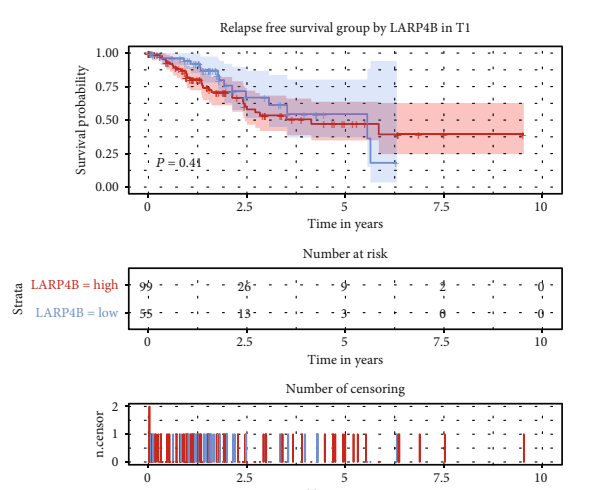

Strata

+ LARP4B $=$ high

+ LARPAB $=$ low

(d)

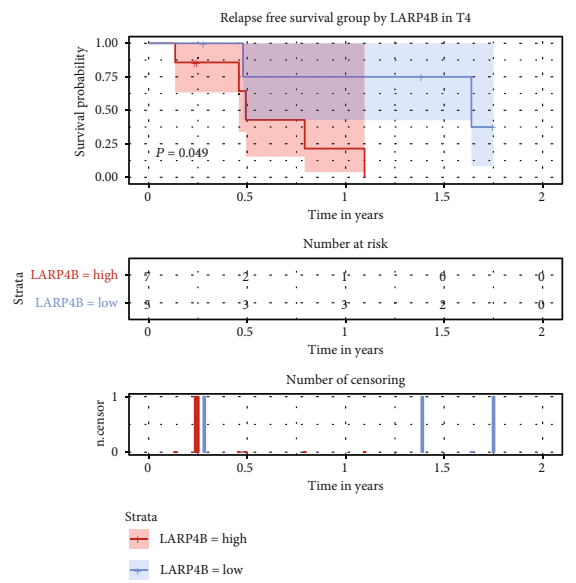

(g)
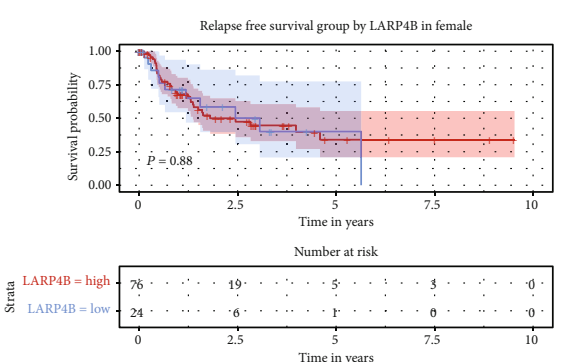

Number of censoring

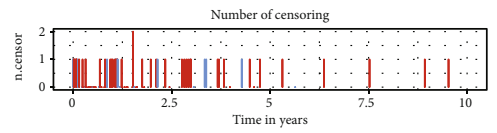

Strata

+ LARP $4 B=$ high

- LARPAB $=$ low

(b)
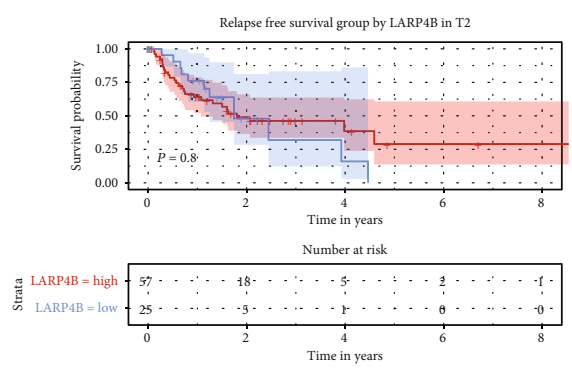

Number of censorin

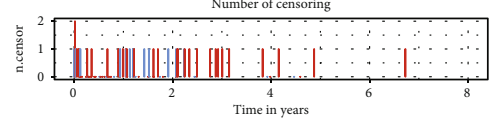

Strat

+ LARP4B $=$ high

+ LARP $4 \mathrm{~B}=10 \mathrm{~W}$

(e)

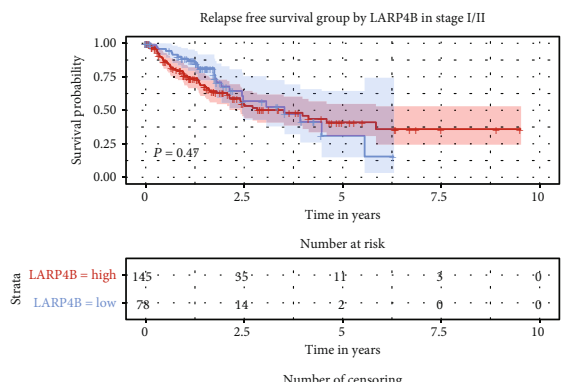

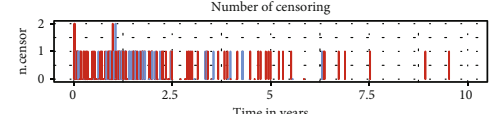

Strata
+ LARP $4 \mathrm{~B}=$ high

- LARPAB $=$ low

(h)

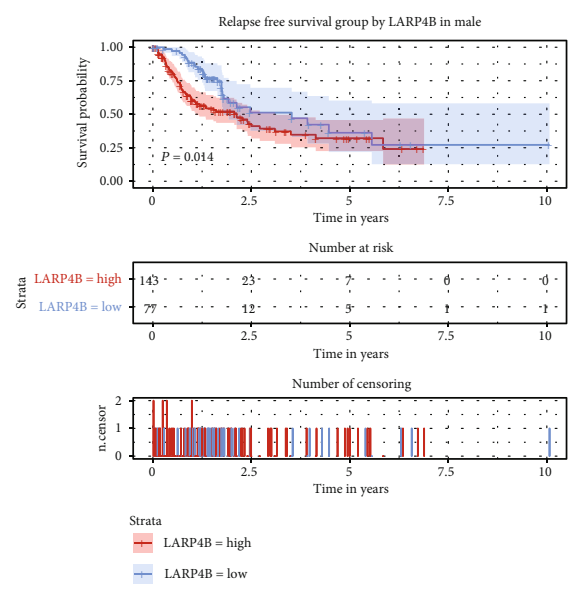

(c)

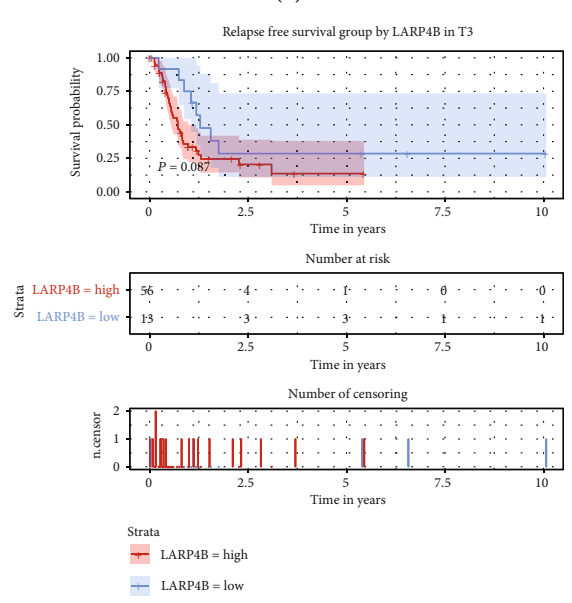

(f)

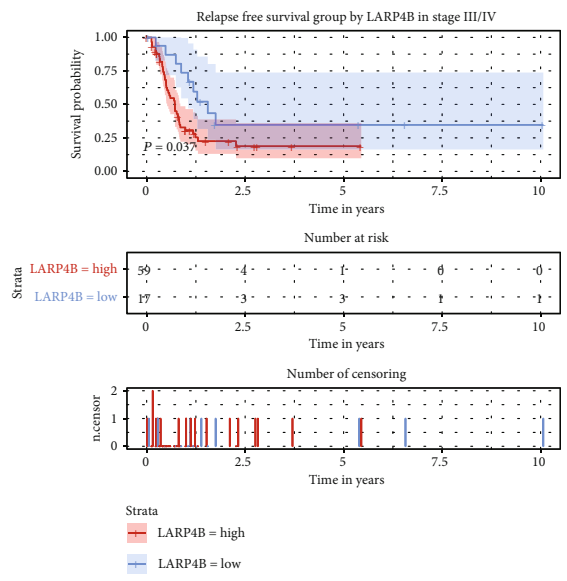

(i)

FIgure 4: Continued. 


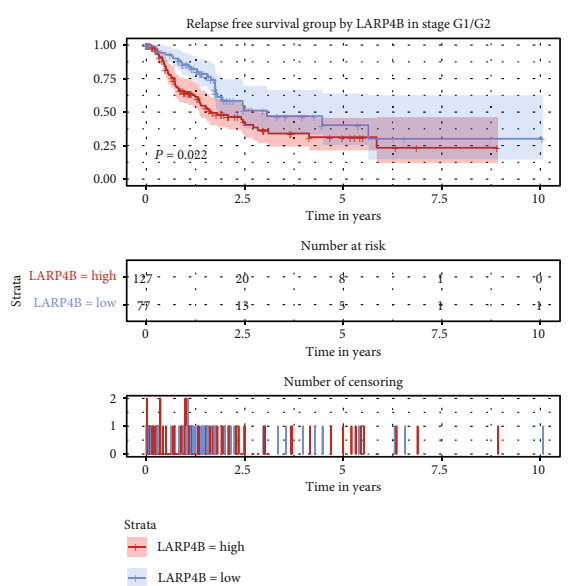

(j)

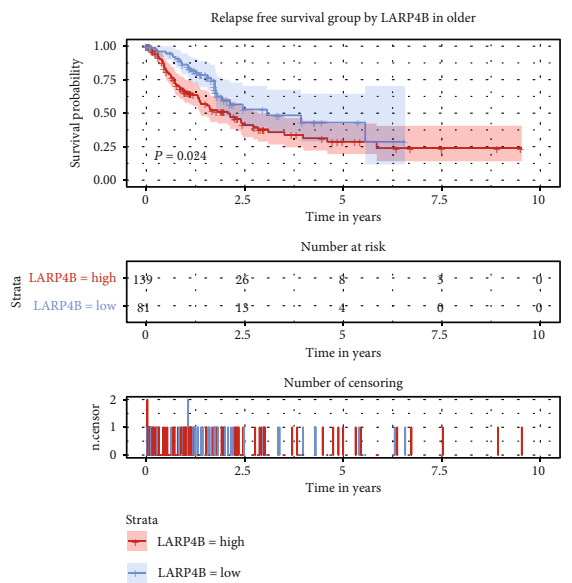

(m)

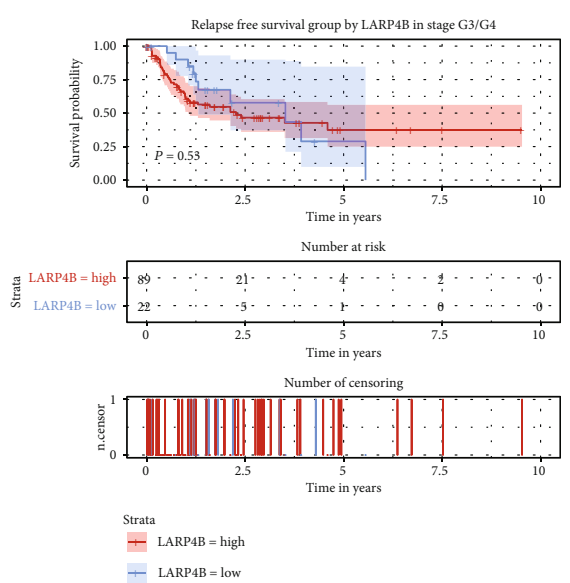

(k)
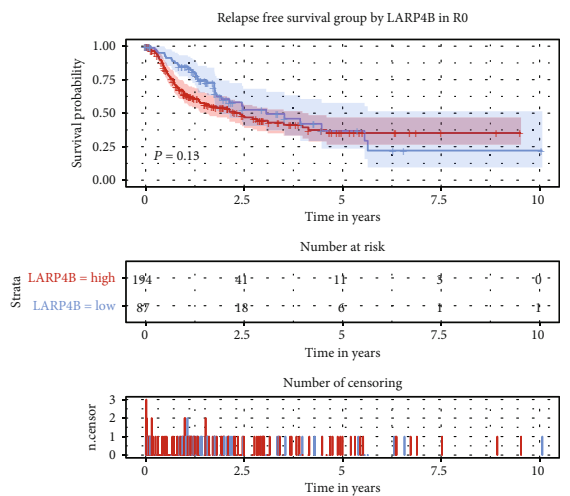

Strata

+ ${ }_{\text {LARP } 4 \mathrm{~B}=\text { high }}$

+ LARPAB $=$ low

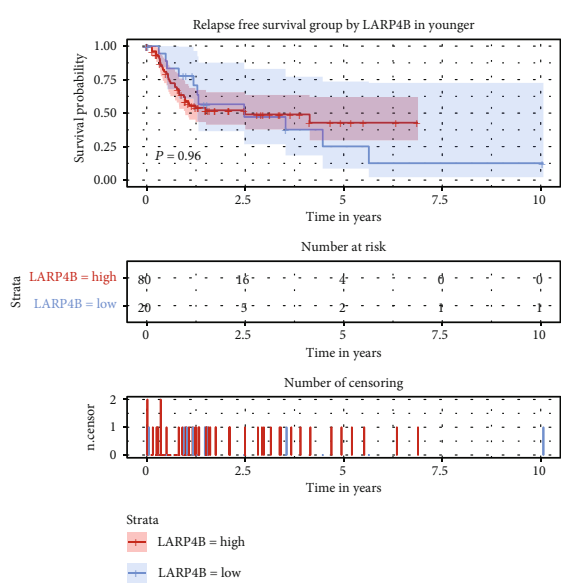

(1)
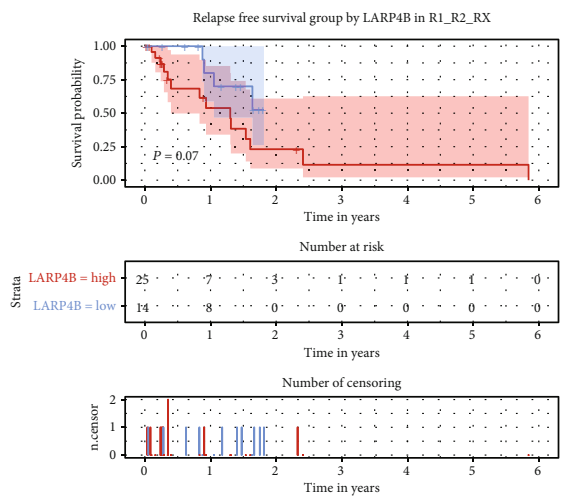

Strata

- ${ }_{\text {LARPAB }}$ hig

- LARPAB = low

(o)

FIGURE 4: Effect of $L A R P 4 B$ expression on relapse-free survival in subgroups of patients with liver cancer. Kaplan-Meier curves of overall survival analysis (a) and subgroup analysis of gender (female and male) (b, c), T classification (T1/T2/T3/T4) (d-g), clinical stage (I/II and III/IV) (h, i), histologic grade (G1/G2 and G3/G4) (j, k), age (younger and older) (l, m), and lymph node dissection (R0 and R1/R2/RX) $(\mathrm{n}, \mathrm{o})$.

TABLE 4: Summary of univariate and multivariate Cox regression analyses of relapse-free survival duration.

\begin{tabular}{|c|c|c|c|c|c|c|}
\hline \multirow{2}{*}{ Parameters } & \multicolumn{3}{|c|}{ Univariate analysis } & \multicolumn{3}{|c|}{ Multivariate analysis } \\
\hline & Hazard ratio & 95\% CI (lower upper) & $P$ value & Hazard ratio & 95\% CI (lower upper) & $P$ value \\
\hline Age & 0.9 & $0.63-1.28$ & 0.55 & & & \\
\hline Gender & 0.99 & $0.7-1.41$ & 0.966 & & & \\
\hline Histological type & 2.02 & $0.66-6.24$ & 0.22 & & & \\
\hline Histologic grade & 0.98 & $0.8-1.21$ & 0.883 & & & \\
\hline Stage & 1.66 & $1.38-1.99$ & 0 & 1.12 & $0.87-1.44$ & 0.392 \\
\hline $\mathrm{T}$ classification & 1.78 & $1.49-2.12$ & 0 & 1.67 & $1.28-2.17$ & 0 \\
\hline $\mathrm{N}$ classification & 0.97 & $0.67-1.4$ & 0.874 & & & \\
\hline M classification & 1.17 & $0.79-1.74$ & 0.432 & & & \\
\hline Radiation therapy & 0.74 & $0.26-2.16$ & 0.584 & & & \\
\hline Residual tumor & 1.28 & $1.01-1.61$ & 0.042 & 1.31 & $1.03-1.67$ & 0.026 \\
\hline LARP4B & 1.46 & $1.01-2.11$ & 0.045 & 1.46 & $1-2.13$ & 0.048 \\
\hline
\end{tabular}


TABLE 5: Gene sets enriched in phenotype high.

\begin{tabular}{lcccc}
\hline MSigDB collection & Gene set name & NES & NOM $p$ val & FDR $q$ val \\
\hline h.all.v6.2.symbols.gmt & HALLMARK_MITOTIC_SPINDLE & -1.846927 & 0.005917 & 0.205141 \\
h.all.v6.2.symbols.gmt & HALLMARK_G2M_CHECKPOINT & -1.710802 & 0.016293 \\
h.all.v6.2.symbols.gmt & HALLMARK_E2F_TARGETS & -1.583288 & 0.045643 & 0.40425 \\
\hline
\end{tabular}

Notes: gene sets with NOM $P$ value $<0.05$ and FDR $q$ value $<0.25$ are considered as significant. Abbreviations: FDR: false discovery rate; NES: normalized enrichment score; NOM: nominal.

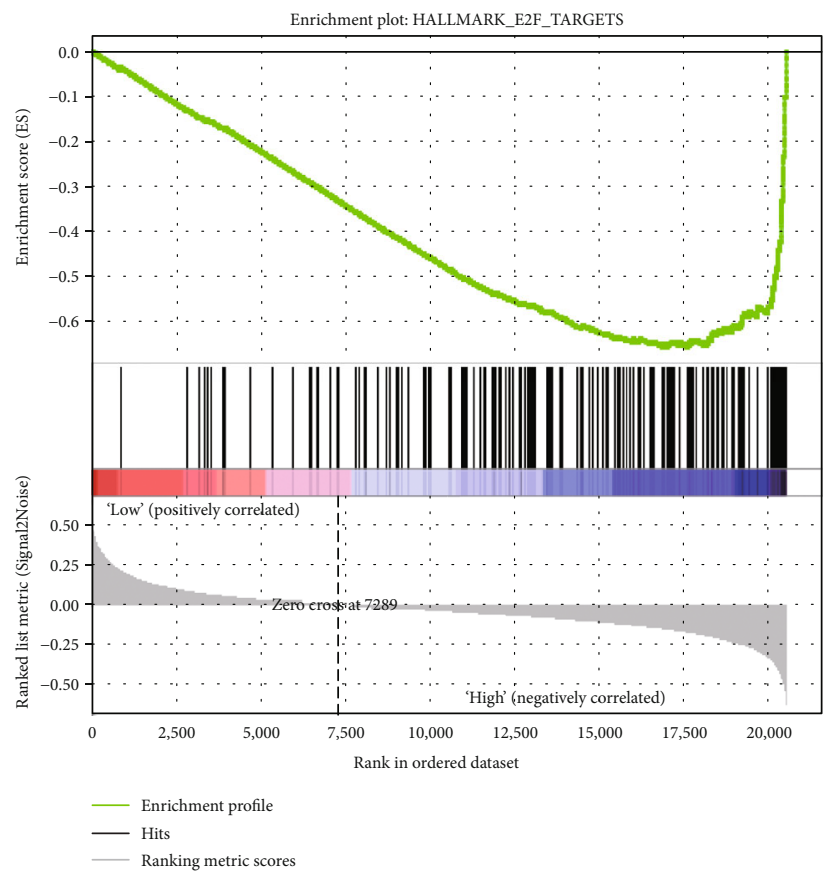

(a)

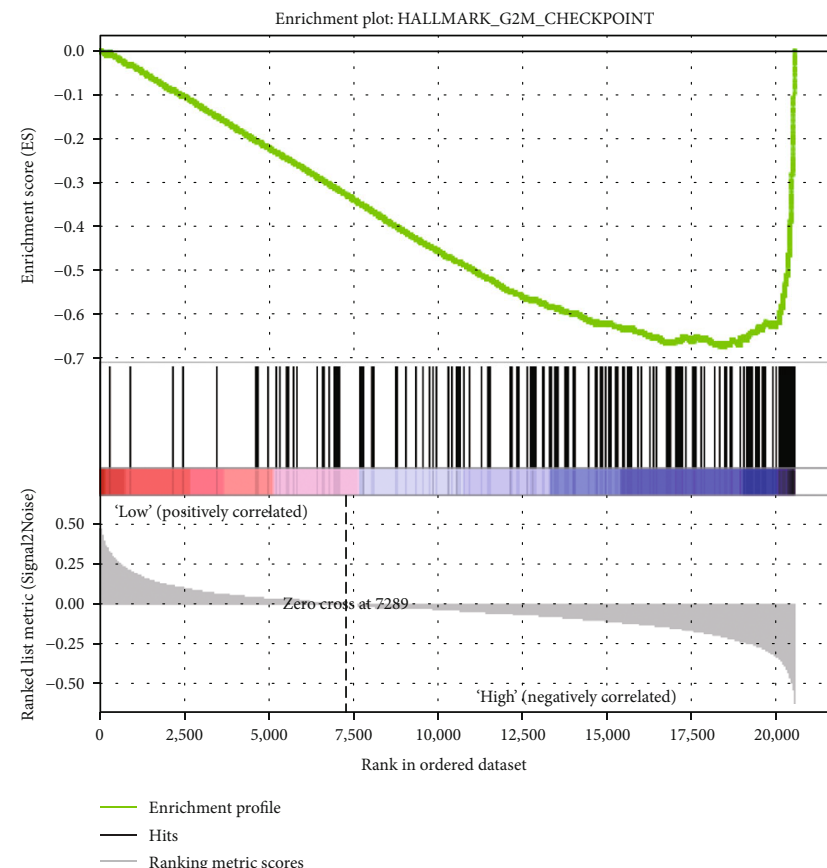

(b)

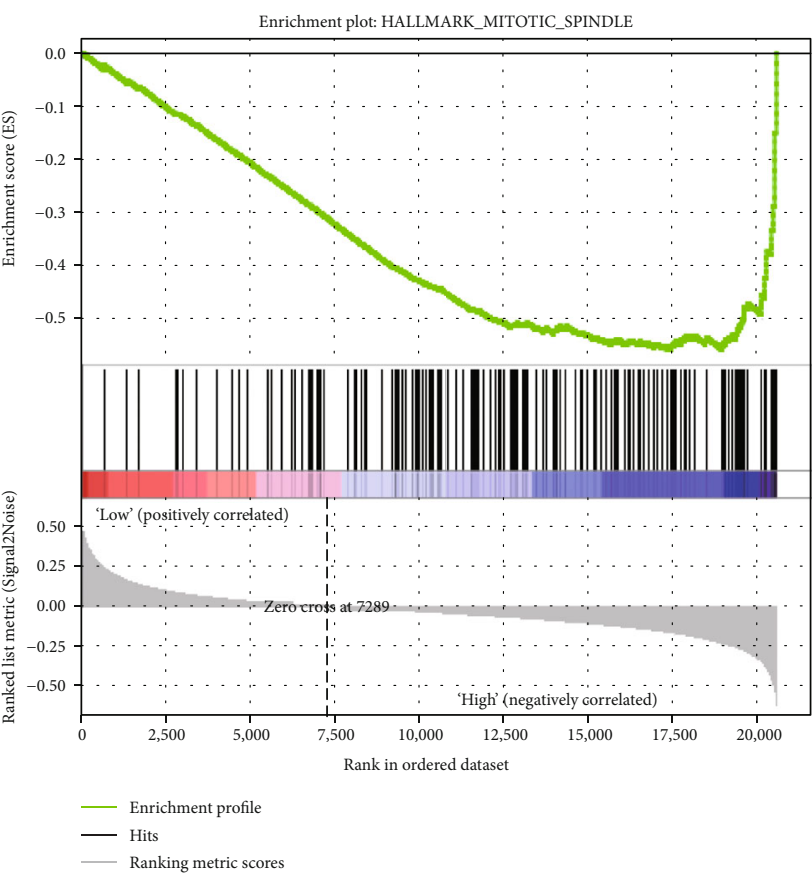

(c)

FIGURE 5: Enrichment plots from GSEA. E2F targets, the G2M checkpoint, and the mitotic spindle pathway were differentially enriched in LARP4B-related liver cancer patients. 
have plans for complex experiments to explore the mechanism further.

\section{Data Availability}

We obtained patient information from an open TCGA database. No private clinical studies or patient data were included in this study.

\section{Conflicts of Interest}

None of the authors have any conflicts of interest.

\section{Acknowledgments}

We thank Michelle Kahmeyer-Gabbe, PhD, from Liwen Bianji, Edanz Editing China (http://www.liwenbianji.cn/ac), for editing the English text of a draft of this manuscript. The project was funded by the Bethune Program of Jilin University (2018A02), Jilin Department of Health (2018J061), and basic research fees.

\section{References}

[1] R. L. Siegel, K. D. Miller, and A. Jemal, "Cancer statistics, 2019," CA: A Cancer Journal for Clinicians, vol. 69, no. 1, pp. 7-34, 2019.

[2] K. A. Cronin, A. J. Lake, S. Scott et al., "Annual Report to the Nation on the Status of Cancer, part I: national cancer statistics," Cancer, vol. 124, no. 13, pp. 2785-2800, 2018.

[3] L. Li and H. Wang, "Heterogeneity of liver cancer and personalized therapy," Cancer Letters, vol. 379, no. 2, pp. 191-197, 2016.

[4] J. Dawkins and R. M. Webster, "The hepatocellular carcinoma market," Nature Reviews Drug Discovery, vol. 18, no. 1, pp. 13$14,2019$.

[5] M. F. Bonaldo, G. Lennon, and M. B. Soares, "Normalization and subtraction: two approaches to facilitate gene discovery," Genome Research, vol. 6, no. 9, pp. 791-806, 1996.

[6] C. Bousquet-Antonelli and J. M. Deragon, "A comprehensive analysis of the La-motif protein superfamily," $R N A$, vol. 15, no. 5, pp. 750-764, 2009.

[7] M. A. Bayfield, R. Yang, and R. J. Maraia, "Conserved and divergent features of the structure and function of $\mathrm{La}$ and La-related proteins (LARPs)," Biochimica et Biophysica Acta (BBA) - Gene Regulatory Mechanisms, vol. 1799, no. 5-6, pp. 365-378, 2010.

[8] A. Castello, B. Fischer, K. Eichelbaum et al., "Insights into RNA biology from an atlas of mammalian mRNA-binding proteins," Cell, vol. 149, no. 6, pp. 1393-1406, 2012.

[9] C. Stavraka and S. Blagden, "The La-related proteins, a family with connections to cancer," Biomolecules, vol. 5, no. 4, pp. 2701-2722, 2015.

[10] H. Koso, H. Yi, P. Sheridan et al., "Identification of RNAbinding protein LARP4B as a tumor suppressor in glioma," Cancer Research, vol. 76, no. 8, pp. 2254-2264, 2016.

[11] Team RDCJC, $R:$ A language and environment for statistical computing, vol. 14, R Foundation for Statistical Computing, Vienna, Austria, 2009.
[12] C. Ginestet, "ggplot2: elegant graphics for data analysis," Journal of the Royal Statistical Society: Series A (Statistics in Society), vol. 174, no. 1, pp. 245-246, 2011.

[13] X. Robin, N. Turck, A. Hainard et al., "pROC: an open-source package for R and S+ to analyze and compare ROC curves," BMC Bioinformatics, vol. 12, no. 1, p. 77, 2011.

[14] T. M. Therneau, “A package for survival analysis in S. 2015,” $R$ Package Version, vol. 2, p. 280, 2017.

[15] T. M. Therneau and P. M. Grambsch, Modeling Survival Data: Extending the Cox Model, vol. 97, Springer, New York, 2000.

[16] A. Subramanian, P. Tamayo, V. K. Mootha et al., "Gene set enrichment analysis: a knowledge-based approach for interpreting genome-wide expression profiles," Proceedings of the National Academy of Sciences of the United States of America, vol. 102, no. 43, pp. 15545-15550, 2005.

[17] A. B. Ryerson, C. R. Eheman, S. F. Altekruse et al., "Annual Report to the Nation on the Status of Cancer, 1975-2012, featuring the increasing incidence of liver cancer," Cancer, vol. 122, no. 9, pp. 1312-1337, 2016.

[18] Y. Jiao, Z. Fu, Y. Li, L. Meng, and Y. Liu, "High EIF2B5 mRNA expression and its prognostic significance in liver cancer: a study based on the TCGA and GEO database," Cancer Management and Research, vol. 10, pp. 6003-6014, 2018.

[19] Y. Jiao, Z. Fu, Y. Li, W. Zhang, and Y. Liu, “Aberrant FAM64A mRNA expression is an independent predictor of poor survival in pancreatic cancer," PloS One, vol. 14, no. 1, p. e0211291, 2019.

[20] Y. Jiao, Y. Li, Z. Lu, and Y. Liu, "High trophinin-associated protein expression is an independent predictor of poor survival in liver cancer," Digestive Diseases and Sciences, vol. 64, no. 1, pp. 137-143, 2019.

[21] M. I. Almeida, M. S. Nicoloso, L. Zeng et al., "Strand-specific miR-28-5p and miR-28-3p have distinct effects in colorectal cancer cells," Gastroenterology, vol. 142, no. 4, pp. 886896.e889, 2012.

[22] Y. Jiao, Y. Li, S. Liu, Q. Chen, and Y. Liu, "ITGA3 serves as a diagnostic and prognostic biomarker for pancreatic cancer," OncoTargets and Therapy, vol. 12, pp. 4141-4152, 2019.

[23] Y. Li, Y. Jiao, Z. Fu, Z. Luo, J. Su, and Y. Li, "High miR-454-3p expression predicts poor prognosis in hepatocellular carcinoma," Cancer Management and Research, vol. 11, pp. 27952802, 2019.

[24] X. Wu, P. A. Northcott, A. Dubuc et al., "Clonal selection drives genetic divergence of metastatic medulloblastoma," Nature, vol. 482, no. 7386, pp. 529-533, 2012.

[25] E. P. Rahrmann, A. L. Watson, V. W. Keng et al., "Forward genetic screen for malignant peripheral nerve sheath tumor formation identifies new genes and pathways driving tumorigenesis," Nature Genetics, vol. 45, no. 7, pp. 756-766, 2013.

[26] H. Takeda, Z. Wei, H. Koso et al., "Transposon mutagenesis identifies genes and evolutionary forces driving gastrointestinal tract tumor progression," Nature Genetics, vol. 47, no. 2, pp. 142-150, 2015.

[27] P. A. Pérez-Mancera, A. G. Rust, L. van der Weyden et al., "The deubiquitinase USP9X suppresses pancreatic ductal adenocarcinoma," Nature, vol. 486, no. 7402, pp. 266-270, 2012.

[28] P. Icard, L. Fournel, Z. Wu, M. Alifano, and H. Lincet, "Interconnection between metabolism and cell cycle in cancer," Trends in Biochemical Sciences, vol. 44, no. 6, pp. 490-501, 2019. 
[29] M. Fischer and G. A. Muller, "Cell cycle transcription control: DREAM/MuvB and RB-E2F complexes," Critical Reviews in Biochemistry and Molecular Biology, vol. 52, no. 6, pp. 638662, 2017.

[30] R. Fraschini, "Factors that control mitotic spindle dynamics," Advances in Experimental Medicine and Biology, vol. 925, pp. 89-101, 2017.

[31] A. Krempler, D. Deckbar, P. A. Jeggo, and M. Lobrich, “An Imperfect G2M Checkpoint Contributes to Chromosome Instability Following Irradiation of S and G2Phase Cells," Cell Cycle, vol. 6, no. 14, pp. 1682-1686, 2007.

[32] Y. Zhang, L. Peng, T. Hu et al., "La-related protein 4B maintains murine MLL-AF9 leukemia stem cell self-renewal by regulating cell cycle progression," Experimental Hematology, vol. 43, no. 4, pp. 309-318.e302, 2015.

[33] S. Mattijssen and R. J. Maraia, "LARP4 is regulated by tumor necrosis factor alpha in a tristetraprolin-dependent manner," Molecular and Cellular Biology, vol. 36, no. 4, pp. 574-584, 2016. 


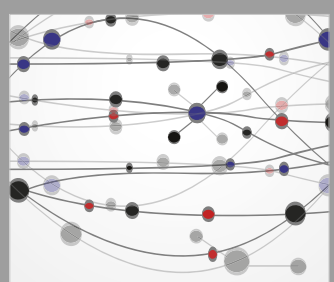

The Scientific World Journal
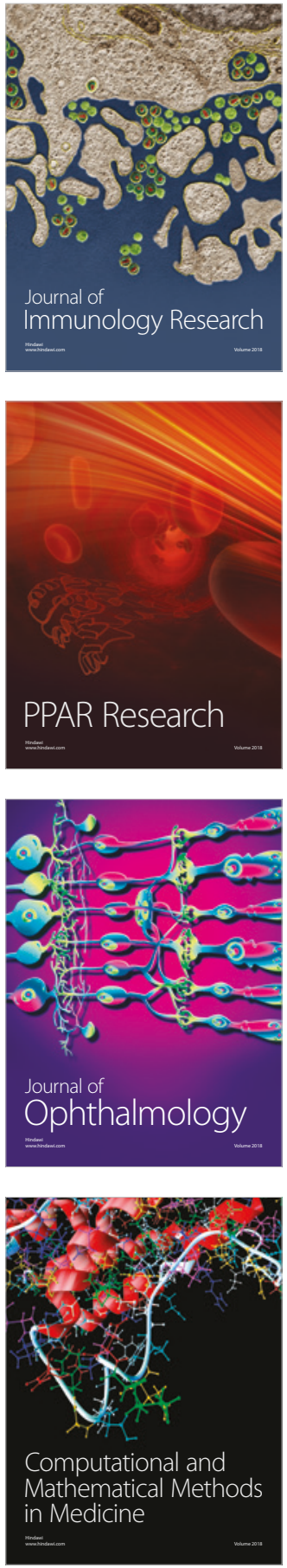

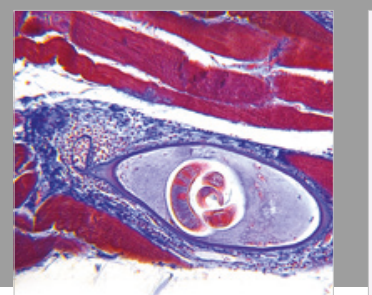

Gastroenterology Research and Practice

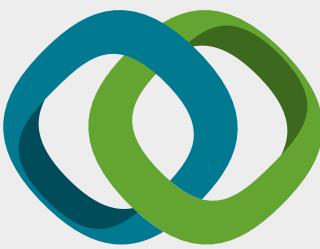

\section{Hindawi}

Submit your manuscripts at

www.hindawi.com
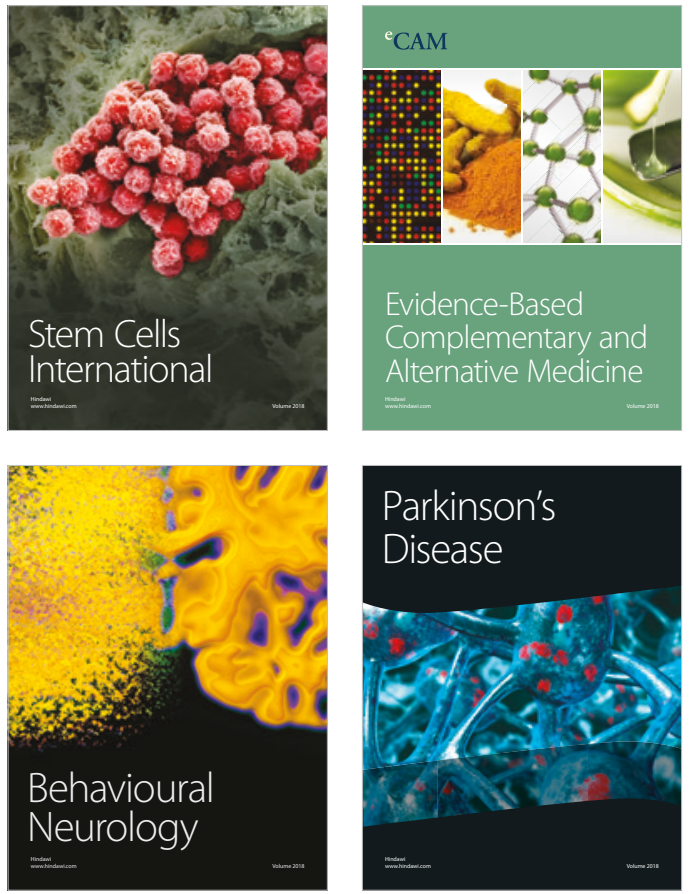

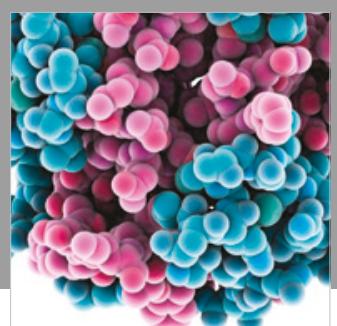

ournal of

Diabetes Research

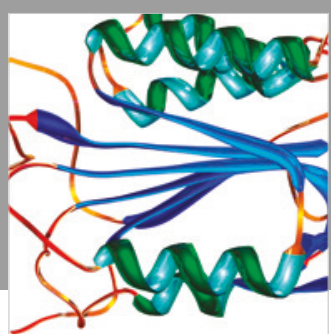

Disease Markers
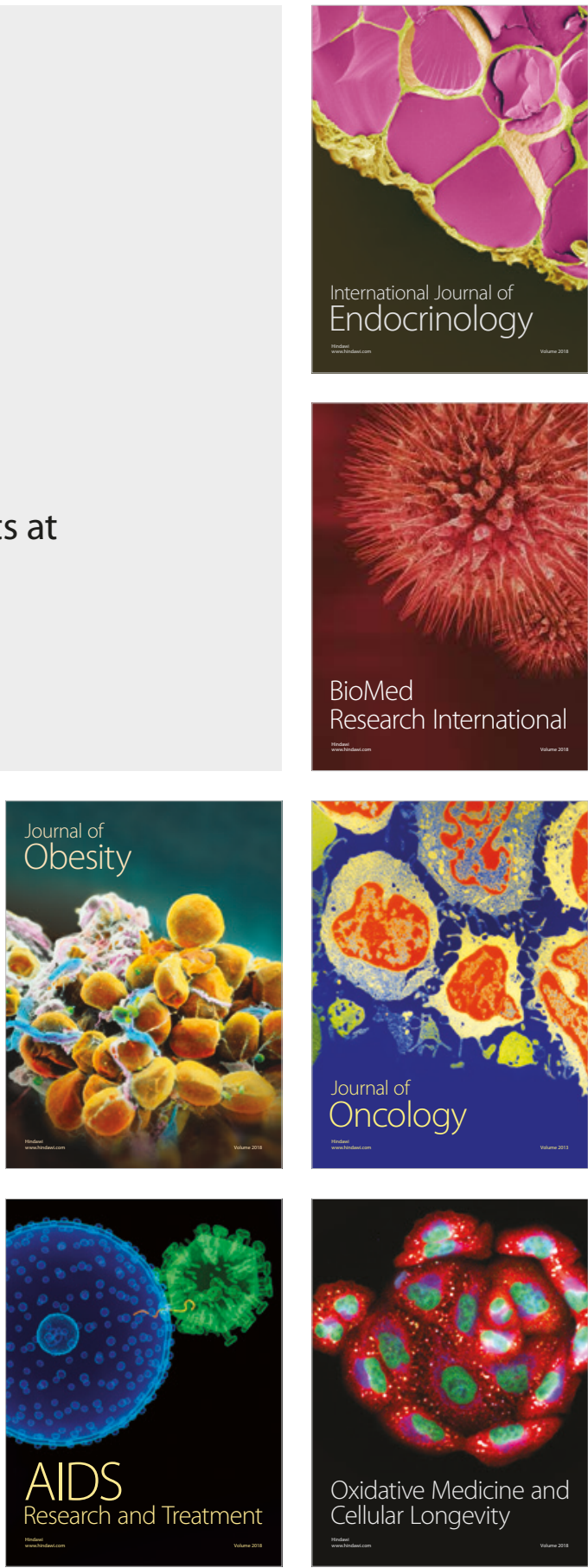